recognized external, non-proprietary standards. The company uses Microsoft standards, as does its main competitor, Spotfire in Somerville, Massachusetts. This offers the end-user additional benefits. "The fact that both companies are developing to a common standard means that although they're competing head-tohead, users can integrate their products however they wish," says Kahn.

\section{The shape of things to come}

Libraries of small-molecule compounds are the raw material that goes into the primary screens. Although there is general agreement about how assay platforms should be developing, there seems to be little consensus about the shape of the ideal compound library. Opinions vary on how big a library should be, and how companies should design, store and handle its contents.

One idea that is exciting interest is to profile and filter compounds for drug-like properties such as solubility and lipophilicity before they ever get into the library. This should give medicinal chemists an easier time by ensuring that lead compounds need less refinement to turn them into drugs.

Companies such as Argenta Discovery, a medicinal chemistry design and screening company based in Harlow, UK, are now screening compounds for a range of drug-like behaviours before they enter the company's libraries. Chris Newton, chief scientific officer at Argenta, describes the profiling as "multi-parametric optimization”.

Early whittling away of compounds with undesirable properties can also be done by computer, and in silico screening for 'drug-likeness' is a central component of the 'virtual-screening' strategies of companies such as Argenta, De Novo Pharmaceuticals in Cambridge, UK, and Vertex Pharmaceuticals in Cambridge, Massachusetts. "We're trying to encode the common sense of medicinal chemists into the computer," says Mark Namchuk, head of high-throughput screening at Vertex. The company uses a proprietary program called REOS (rapid elimination of swill) to eliminate non-drug-like molecules before compounds make it through to the primary screen.

It is too early to judge the success of virtual-screening programmes, but two independent teams of researchers, from Merck laboratories in Rahway, New Jersey, and from Brian Shoichet's group at Northwestern University, have shown structure-based computational docking used as a filter can hugely enrich the hit rate compared with random screening.

\section{Compounds on display}

One area of chemical screening where the drive towards automation has been somewhat weak is compound handling.

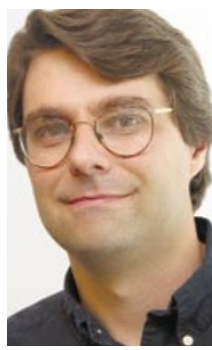

Namchuk:

screens are

experiments.
The preparation of microtitre plates placing the various compounds into their appropriate wells ready for screening — is still relatively slow. Graffinity

Pharmaceuticals, a drug-discovery company based in Heidelberg, Germany, has come up with an alternative strategy. It

sprays 10,000 compounds as spots onto a 'chip', and their affinity for a target protein can be read simultaneously by an imager based on the surface plasmon resonance method developed by equipment manufacturer Biacore in Uppsala, Sweden (see "Fragmenting the problem", page 459).

Graffinity's early microarrays were made up of binary combinations of monomers using amide coupling, as these are easy to make and can rapidly generate a large library of compounds. The company now has a more diverse library of 70,000 compounds presented on microarrays. These can be screened against a protein target in a day, requiring just $5 \mathrm{mg}$ of protein.

This microarray platform generates a relatively high number of hits, but many of them will be for compounds with similar structures, because the screen

\title{
HOW SMALL SHOULD YOU GO?
}

Miniaturization has been one of the triumphs in screening technology over the past decade or so, mainly because of advances in the automation of liquid handling, control software and detection systems. A few examples of ultra-high-throughput screening already exist, with Vertex in San Diego, California, for instance, performing the majority of its assays using 3,456-well microplates, in which each assay is done in a volume of just $1 \mu \mathrm{l}$.

Affymax, a drug-discovery firm based in Palo Alto, California, is reported to be working on a 20,000-well plate in which each well would have a volume of just $25 \mathrm{nl}$. And although most of the endeavour has been directed towards miniaturizing microplates, other ultra-high-throughput formats are being developed, the screening of microbead-attached combinatorial libraries, for instance, by companies such as Luminex in Austin, Texas, and Illumina in San Diego, California.

Although these examples are undoubtedly a taste of the future, miniaturization is not for everyone, and does not suit every purpose. Except when compound or protein amounts are critical factors, miniaturization is unlikely to make a big difference to the efficiency of primary screening, although doing assays in less time makes it easier to keep conditions standardized.

For Vertex's cell-based assays, the transition from 384- to 3,456-well plates meant that the number of cells needed dropped from $10,000-40,000$ per well to about 200 . This means that the company can work with cell types that are relatively difficult to get hold of, such as disease cells, says Paul Negulescu (below), vicepresident of discovery biology at Vertex. In principle, 3,456-well plates could be used to study single cells, but at that level the cells' 'individuality' starts to become a problem, giving uneven responses and so degrading the data.

Vertex's 3,456-well Nanowell plates enable ultra-high throughput.
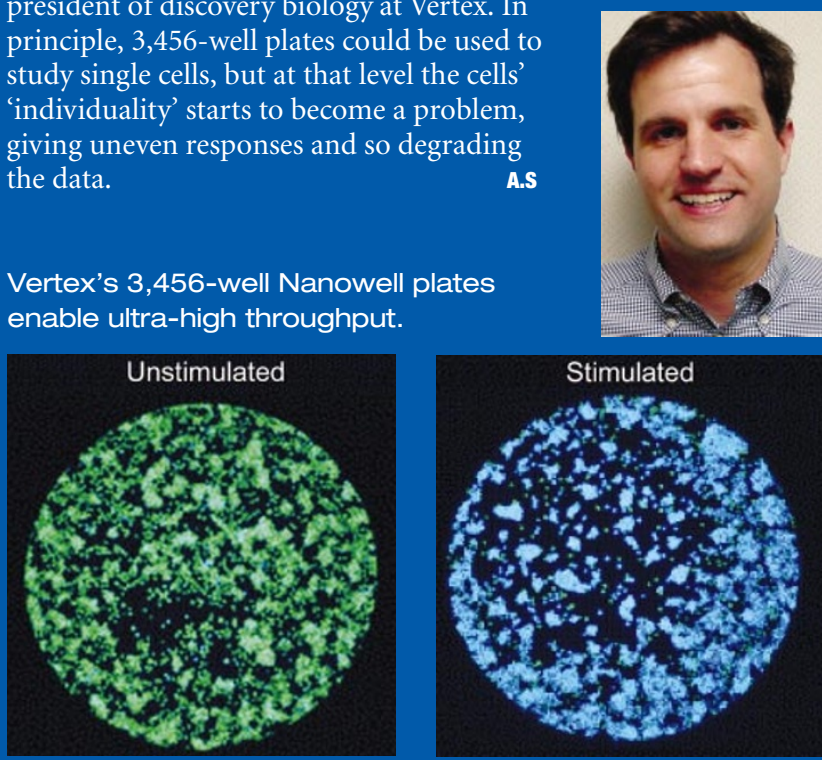